\title{
The effect of radial fins on the uplift resistance of buried pipelines
}

\author{
J. G. TOM*, C. D. O’LOUGHLIN*, D. J. WHITE*, A. HAGHIGHI† and A. MACONOCHIE†
}

This paper investigates the potential for increasing the uplift resistance of buried pipelines through the addition of radial fins on the pipe circumference. Experiments conducted in loose sand showed that fins extending by $20 \%$ of the pipe diameter increase the vertical peak uplift resistance by up to $25 \%$, depending on embedment depth and fin configuration. A limit equilibrium solution - based on known values of peak friction and dilation angles - predicts the uplift resistance within 13\% of the measurements. The trends of peak uplift resistance with embedment and fin configuration were also replicated in numerical analyses conducted using a non-associated Mohr-Coulomb soil model. The numerically predicted peak uplift resistances were within 10 and $21 \%$ of the experimental values for rough and smooth interfaces, respectively. Soil failure mechanisms from the numerical analyses were broadly consistent with that assumed in the limit equilibrium solution. However, the experimentally observed mechanisms differed subtly, with a limited extent of lifted soil above the pipe and circulatory flow occurring from above to beneath the pipe. This mechanism was approached in the numerical analyses for a smooth interface by specifying a small negative dilation angle, which had minimal effect on the predicted peak uplift resistance.

KEYWORDS: limit equilibrium methods; offshore engineering; pipes \& pipelines

ICE Publishing: all rights reserved

\section{NOTATION}

$C$ cover height, defined as the vertical distance from the top of the pipe to the soil surface

$D$ pipe diameter

$D^{\prime}$ total lateral extent of fins

$E$ fin length

$H$ embedment depth, defined as the vertical distance from the centre of the pipe to the soil surface

$H^{\prime}$ distance from soil surface to deepest lateral fin

$K_{0} \quad$ lateral earth pressure coefficient at rest

$N_{\gamma} \quad$ uplift factor

$P \quad$ uplift resistance

$R_{\mathrm{d}} \quad$ relative density

$\gamma^{\prime} \quad$ soil effective unit weight

$\delta z \quad$ vertical displacement

$\theta$ angle of lateral fins relative to the pipe waist

$\sigma_{\mathrm{nf}}$ normal force on shear planes

$\tau_{\text {peak }} \quad$ shear force on shear planes

$\phi$ friction angle

$\psi \quad$ dilation angle

\section{INTRODUCTION}

The soil resistance during upward movement of a buried pipeline is a key design consideration for much oil and gas infrastructure and many urban lifelines. Offshore pipelines are often buried for protection. Burial provides constraint against upheaval buckling for pipelines operating at high temperature and pressure. Onshore pipelines in earthquakeprone areas often rely on soil uplift resistance to avoid flotation in liquefaction events. It is therefore necessary to ensure adequate uplift resistance in design, while avoiding an excessive cover (burial) depth.

Manuscript received 29 September 2016; first decision 12 December 2016; accepted 14 December 2016.

Published online at www.geotechniqueletters.com on 17 January 2017.

${ }^{*}$ Centre for Offshore Foundation Systems, The University of Western Australia, Crawley, WA, Australia.

$\dagger$ Technip UK Ltd, Aberdeen, UK.
For sandy soils, previous work has established various prediction methods for uplift resistance, based on the soil unit weight, friction angle and sometimes also using a dilation angle. These methods are based empirically on model tests (Trautmann et al., 1985), or use plasticity limit analysis (Merifield \& Sloan, 2006) or limit equilibrium solutions (White et al., 2008a). In drained conditions, limit analysis can be unrealistic due to the assumption of associated flow. Drescher \& Detournay (1993) suggested modifications to classical limit analysis to estimate limit loads, and Smith (2012) provided example solutions for buried plate anchors. For pipelines, numerical studies have also explored the effect of non-associativity on uplift resistance (e.g. Vanden Berghe et al., 2005). Prediction methods for peak uplift resistance in sand are generally based on a failure mechanism involving straight slip planes from the pipe to the soil surface, with different assumptions regarding the inclination of these planes and the normal stress on them.

Pipeline burial design typically involves optimisation of pipeline cover depth for a given soil and pipeline properties. To avoid expensive deep burial, alternative methods of increasing the uplift resistance are sought.

This experimental and numerical study investigates the potential use of radial fins on a pipeline (where the fins would extend longitudinally along a section of the pipe) to increase the uplift resistance. The study compares bare pipes with pipes featuring fins of different sizes and orientations, and also provides a detailed insight into the mobilised displacement mechanism of soil during uplift. These results inform the efficiency of fins to add uplift resistance, while also providing insight into the validity of the slip plane model used to assess the peak uplift resistance of the pipe.

\section{METHODOLOGY \\ Experimental arrangement}

The experiments were conducted at the University of Western Australia in test containers with internal dimensions 
of $226 \mathrm{~mm} \times 338 \mathrm{~mm} \times 299 \mathrm{~mm}$. Two of the opposing vertical end walls of the container were manufactured from $25 \mathrm{~mm}$ thick Perspex panels. This allowed photography of the exposed soil plane using a five-megapixel resolution machine vision camera controlled by in-house software (Stanier \& White, 2013). The images were subsequently analysed using particle image velocimetry (PIV) software (Stanier et al., 2016) to determine the soil displacement patterns. The experimental arrangement is shown in Fig. 1(a).

Uplift movement was controlled by an actuator mounted on the test container and controlled by way of Labview software (De Catania et al., 2010). A loading arm was attached rigidly to the actuator and an S-shaped load cell with a measurement range of $500 \mathrm{~N}$ was attached to the base of the loading arm to measure the vertical load using an in-house data acquisition system (Gaudin et al., 2009). A lifting cradle was attached below the load cell, and the actuator axes adjusted such that this cradle was positioned under a lifting rod connected to the buried pipeline, allowing the pipeline to be loaded vertically without introducing moment (Fig. 1(b)).

\section{Model pipelines}

Five cylindrical model pipelines with an external diameter of $50 \mathrm{~mm}$ and a length of $225 \mathrm{~mm}$ were fabricated from aluminium for the experiments. The arrangement of radial fins used on four of the pipelines is shown in Fig. 2 (with dimensions as described in Fig. 3).

\section{Test materials and model preparation}

A commercially produced uniform 'super-fine' silica sand with a median particle size $\left(D_{50}\right)$ of $\sim 0 \cdot 19 \mathrm{~mm}$ was used, with the properties given in Table 1 . All samples were prepared by air pluviation of dry sand to a target relative density of $R_{\mathrm{d}}=25 \pm 2 \%$.

\section{Experimental programme}

A total of 18 uplift tests were conducted. A series of 15 tests were conducted with the model pipe oriented with the ends away from the container walls to allow for reliable quantification of uplift resistance without the influence of sidewall friction. Each pipe configuration was tested at three different pipeline cover ratios $(C / D=2,3,4)$, as described schematically in Fig. 3. Further tests were conducted with pipe ends oriented towards the Perspex walls for observation and measurement of soil movement during uplift at a cover ratio, $C / D=3$.

Smooth end caps were used to cover the pipe ends during the non-PIV tests. The pipe ends were covered with flexible foam during PIV testing, to prevent the ingress of sand between the pipe and the window.

The pipes were displaced vertically at a constant velocity of $0.2 \mathrm{~mm} / \mathrm{s}$. Images were captured in PIV tests at a rate of 5 fps (frames per second).

\section{Numerical analysis approach}

Parallel numerical simulations of a subset of the model tests were undertaken using version 2016.05.27 of the finite-element software OptumG2 (OptumCE, 2016). Elastoplastic analyses were undertaken modelling the soil with six-node Gauss elements as cohesionless nonassociated Mohr-Coulomb material with specified constant peak friction angle, dilation angle and soil unit weight. Strength parameters were selected to reproduce the stress and dilation conditions of the experiments. Table 2 summarises the relevant material parameters adopted, which include values of peak friction and dilation angles based on Bolton (1986), calculated from the relative density and constant volume friction angle. The pipeline was modelled as a weightless rigid material. The soil domain boundaries were 2.5 below and 3.5 diameters to the side of the pipe centre for all analyses. Sensitivity studies showed that this soil domain extent was sufficient to eliminate boundary effects.

\section{RESULTS}

\section{Uplift response}

The uplift response observed for the tests with the plain pipe and the larger fins, in each orientation, is shown in Fig. 4. The following features are observed.

- The overall response involves an approximately quadratic reduction in uplift resistance with pipe embedment, which reflects the standard uplift model of shear on slip planes with effective stresses that are proportional to

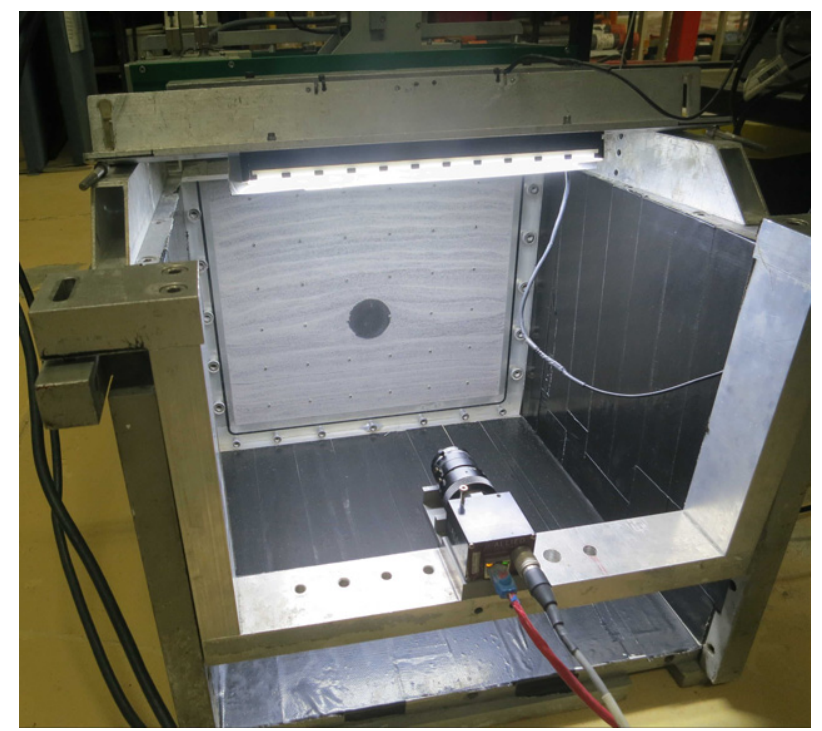

(a)

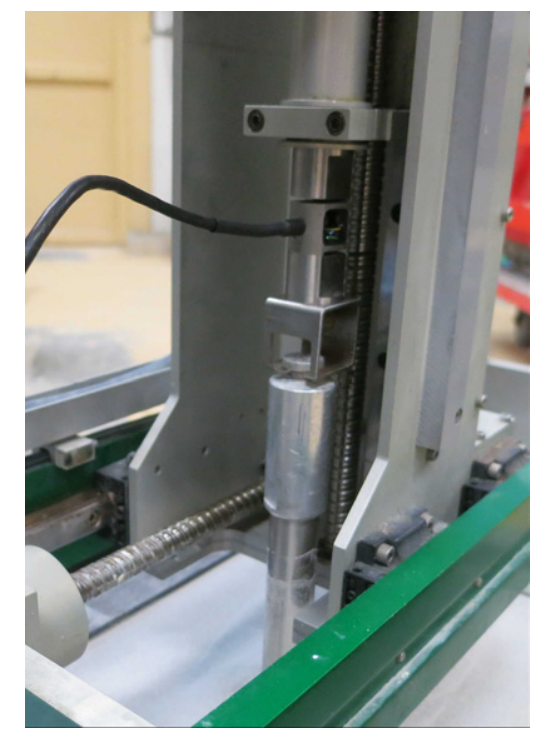

(b)

Fig. 1. Experimental equipment: (a) general arrangement of test container and (b) close-up view of loading apparatus 


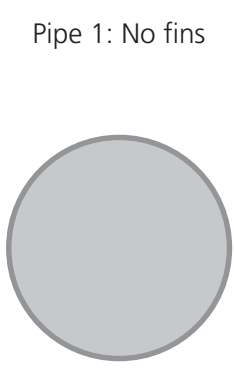

Pipe 2: $E / D=0 \cdot 1-$
centre-up
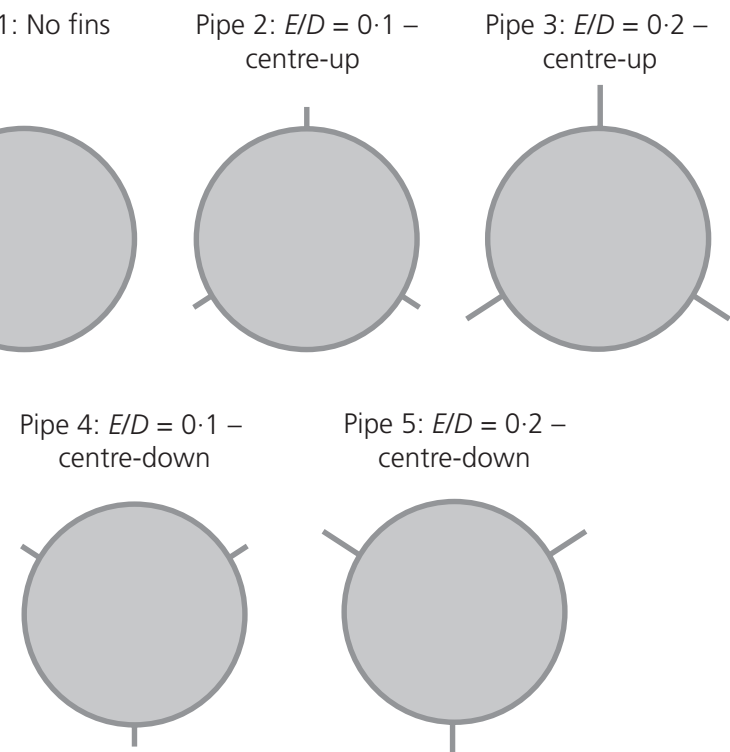

Pipe 5: $E / D=0.2-$ centre-down

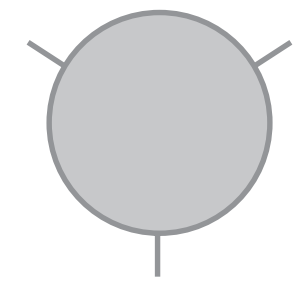

Fig. 2. Tested pipeline configurations

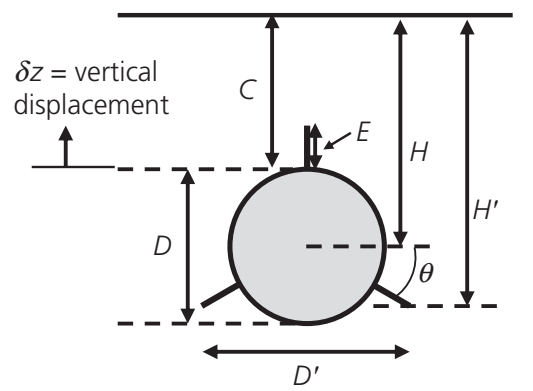

Fig. 3. Definition of geometric notation

depth; as the depth reduces so does the length of, and mean stress on, the slip planes, leading to a quadratic profile.

- During the initial $\sim 10 \%$ of a diameter of movement, a small brittle peak in resistance is also evident, suggesting mobilisation of a peak friction angle. Mobilisation distances to peak uplift resistance are in the range $\delta z_{\text {pipe }} / C=0 \cdot 5-1 \%$ for all cover ratios. When expressed as a fraction of the pipe diameter, this corresponds to $\delta z_{\text {pipe }} / D$ increasing from $1-2 \%$ at $C / D=2$ to $4-8 \%$ at $C / D=4$. These values lie within the range reported in the literature (e.g. as summarised by Ivanović \& Oliphant (2014)), and are higher than the industry guidelines (DNV, 2007) at higher cover ratios.

- Oscillations in resistance are evident immediately after the peak is mobilised. This phenomenon has been observed in previous studies, and is linked to intermittent slumping of sand around the pipe periphery into the voids beneath (Trautmann et al., 1985; Dicken, 1994; Cheuk et al., 2008; O'Loughlin \& Barron, 2012).

\section{Comparison of observed and calculated peak uplift resistance}

The values of peak uplift resistance $\left(P_{\text {peak }}\right)$ from Fig. 4 are summarised in Table 3 . The uplift factors $\left(N_{\gamma}\right)$ in Table 3 are calculated as

$$
N_{\gamma}=\frac{P_{\text {peak }}}{\gamma^{\prime} D(C+D / 2)}
$$

Figure 5(a) shows the change in $N_{\gamma}$, relative to pipe 1 caused by the addition of the fins. The centre-up fin arrangement leads to an average increase in $N_{\gamma}$ by 13 and $21 \%$ for the small $(E / D=0 \cdot 1)$ and large $(E / D=0 \cdot 2)$ fins, respectively. In contrast, the centre-down fin arrangement actually leads to an average reduction in uplift resistance, although this is less evident for the larger fins.

These trends have been replicated in two ways: by way of a limit equilibrium solution for uplift resistance that has been modified to include the fins and by way of numerical modelling.

The limit equilibrium solution involves straight shear planes inclined at an angle of dilation to the vertical, following White et al. (2008a). The normal stress on shear planes is assumed to remain equal to the in situ value given by $K_{0}$ conditions. For the pipes with fins, the shear planes are assumed to originate from the tip of the fins (Fig. 6). The peak shear stress mobilised on developed shear planes is

$$
\tau_{\text {peak }}=\gamma^{\prime} z \tan \left(\phi_{\text {peak }}\right)\left[\frac{1+K_{0}}{2}-\frac{1-K_{0}}{2} \cos (2 \psi)\right]
$$

Integrating this over the length of assumed shear planes and including the weight of soil required to be lifted during

Table 1. Engineering properties of super-fine silica sand (Lee, 2009)

\begin{tabular}{l|l|c|l}
\hline Property & Symbol & Value & Comments \\
\hline Median particle size & $D_{50}: \mathrm{mm}$ & $0 \cdot 19$ & - \\
Specific gravity & $G_{\mathrm{s}}:$ dimensionless & $2 \cdot 65$ & - \\
Maximum void ratio & $e_{\max }:$ dimensionless & $0 \cdot 747$ & Corresponds to a dry unit weight of $\sim 14 \cdot 9 \mathrm{kN} / \mathrm{m}^{3}$ \\
Minimum void ratio & $e_{\min }: \operatorname{dimensionless}$ & $0 \cdot 449$ & Corresponds to a dry unit weight of $\sim 18 \cdot 0 \mathrm{kN} / \mathrm{m}^{3}$ \\
Critical state friction angle & $\phi_{\mathrm{cv}}: \operatorname{deg}$ & 31 & See White et al. $(2008 \mathrm{~b})$ \\
\hline
\end{tabular}

\begin{tabular}{|c|c|c|c|c|c|}
\hline \multirow[t]{2}{*}{ Parameter } & \multirow[t]{2}{*}{ Symbol } & \multirow[t]{2}{*}{ Unit } & \multicolumn{3}{|c|}{ Value } \\
\hline & & & $C / D=2$ & $C / D=3$ & $C / D=4$ \\
\hline $\begin{array}{l}\text { Unit weight } \\
\text { Peak friction angle } \\
\text { Peak dilation angle } \\
\text { Young's modulus } \\
\text { Poisson's ratio }\end{array}$ & $\begin{array}{c}\gamma^{\prime} \\
\phi_{\text {peak }}^{\prime} \\
\psi \\
E_{\mathrm{m}} \\
v\end{array}$ & $\begin{array}{c}\mathrm{kN} / \mathrm{m}^{3} \\
\circ \\
\circ \\
\mathrm{MPa} \\
-\end{array}$ & $\begin{array}{c}15 \cdot 7 \\
37 \cdot 7 \\
8 \cdot 3 \\
20 \\
0 \cdot 2\end{array}$ & $\begin{array}{c}15 \cdot 7 \\
37 \cdot 2 \\
7 \cdot 8 \\
20 \\
0 \cdot 2\end{array}$ & $\begin{array}{c}15 \cdot 7 \\
36 \cdot 9 \\
7 \cdot 4 \\
20 \\
0 \cdot 2\end{array}$ \\
\hline
\end{tabular}

Table 2. Summary of adopted FEA material parameters 


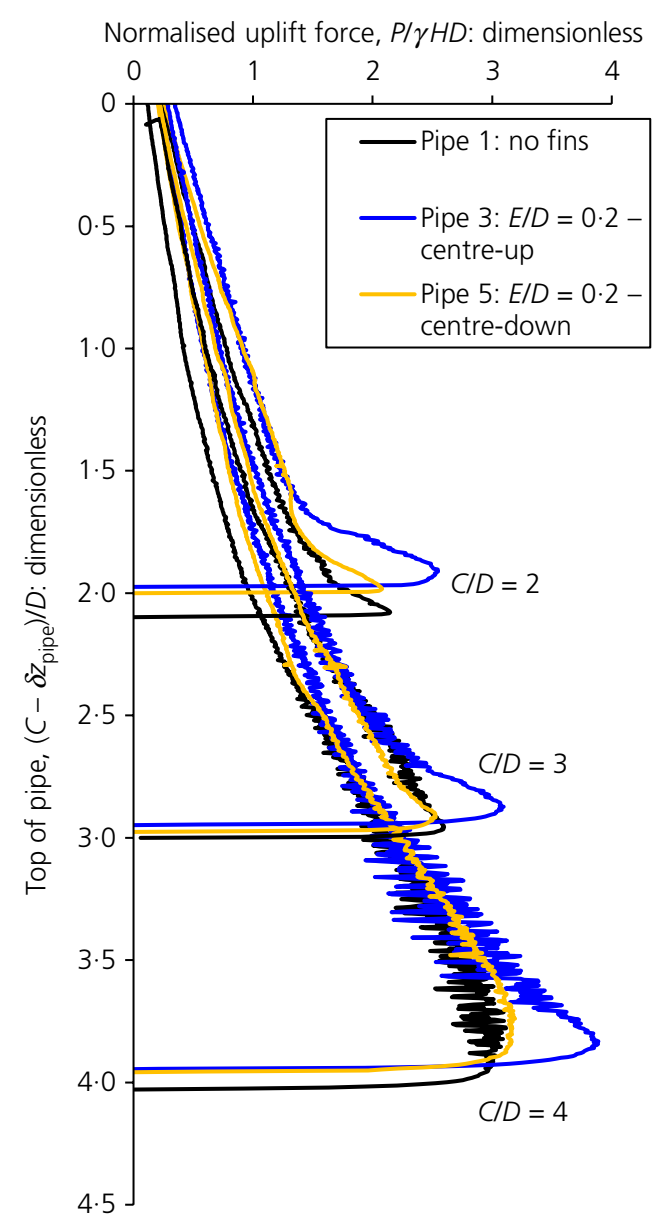

(a)

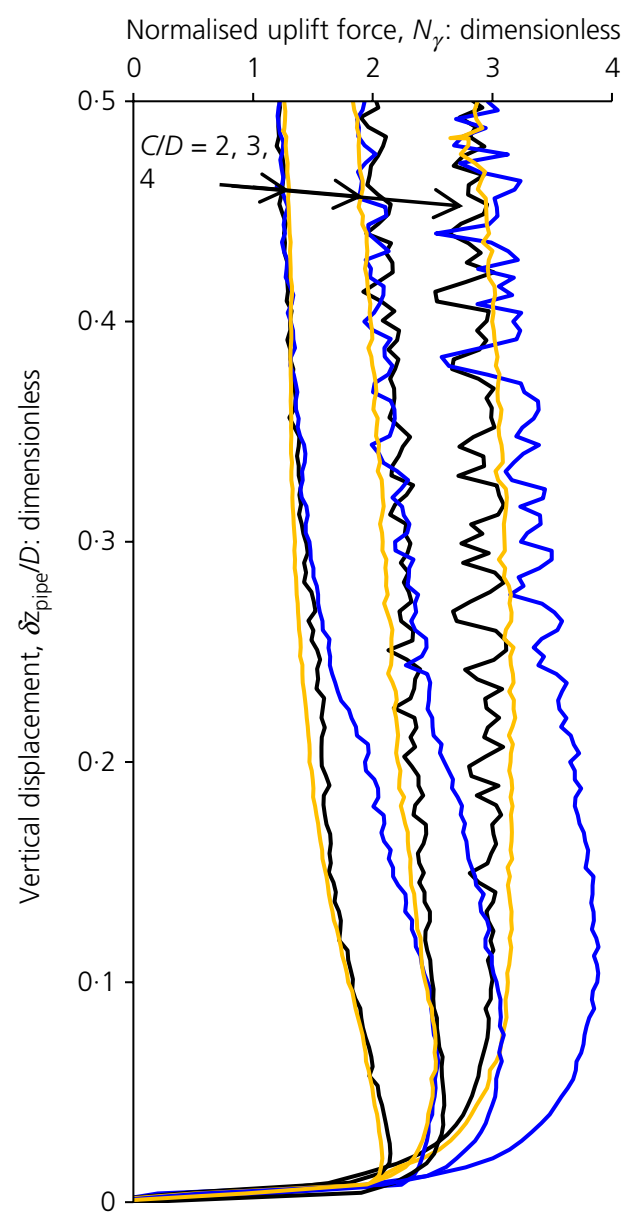

(b)

Fig. 4. Load-displacement response during pipe uplift: (a) overall response and (b) close up of initial response

Table 3. Summary of key uplift test results

\begin{tabular}{|c|c|c|c|c|c|c|c|}
\hline \multirow[t]{2}{*}{$\begin{array}{l}\text { Pipe } \\
\text { type }\end{array}$} & \multirow[t]{2}{*}{ Configuration description } & \multirow[t]{2}{*}{$\begin{array}{l}\text { Cover ratio, } \\
C / D:-\end{array}$} & \multirow[t]{2}{*}{$\begin{array}{l}\text { Peak resistance - } \\
\text { experiment, } P_{\text {peak }}: \mathrm{N}\end{array}$} & \multicolumn{3}{|c|}{$\begin{array}{l}\text { Uplift resistance factor, } \\
N_{\gamma} \text { : dimensionless }\end{array}$} & \multirow{2}{*}{$\begin{array}{c}\text { Experimental } N_{\gamma} \\
\text { normalised by pipe 1: } \\
\text { dimensionless }\end{array}$} \\
\hline & & & & Exp. & Num.* & LE & \\
\hline $\begin{array}{l}1 \\
1 \\
1 \\
3 \\
3 \\
3 \\
5 \\
5 \\
5 \\
5\end{array}$ & $\begin{array}{l}\text { No fins } \\
E / D=0 \cdot 2-\text { centre-up } \\
E / D=0 \cdot 2-\text { centre-down }\end{array}$ & $\begin{array}{l}2 \\
3 \\
4 \\
2 \\
3 \\
4 \\
2 \\
3 \\
4\end{array}$ & $\begin{array}{r}49 \cdot 2 \\
80 \cdot 1 \\
124 \cdot 4 \\
55 \cdot 6 \\
94 \cdot 2 \\
152 \cdot 5 \\
45 \cdot 9 \\
77 \cdot 5 \\
125 \cdot 6\end{array}$ & $\begin{array}{l}2 \cdot 15 \\
2 \cdot 60 \\
3 \cdot 12 \\
2 \cdot 55 \\
3 \cdot 10 \\
3 \cdot 89 \\
2 \cdot 08 \\
2 \cdot 53 \\
3 \cdot 19\end{array}$ & $\begin{array}{l}2 \cdot 12 / 2 \cdot 07 \\
2 \cdot 65 / 2 \cdot 71 \\
3 \cdot 17 / 3 \cdot 33 \\
2 \cdot 81 / 3 \cdot 09 \\
3 \cdot 35 / 3 \cdot 76 \\
3 \cdot 71 / 4 \cdot 31 \\
2 \cdot 01 / 2 \cdot 13 \\
2 \cdot 50 / 2 \cdot 43 \\
2 \cdot 94 / 3 \cdot 11\end{array}$ & $\begin{array}{l}1 \cdot 98 \\
2 \cdot 45 \\
2 \cdot 88 \\
2 \cdot 57 \\
3 \cdot 01 \\
3 \cdot 43 \\
1 \cdot 87 \\
2 \cdot 34 \\
2 \cdot 78\end{array}$ & $\begin{array}{l}1 \\
1 \\
1 \\
1 \cdot 19 \\
1 \cdot 19 \\
1 \cdot 25 \\
0 \cdot 97 \\
0 \cdot 97 \\
1 \cdot 02\end{array}$ \\
\hline
\end{tabular}

*Numerical results for rough/smooth interface.

uplift, the total peak uplift resistance per unit length, $P_{\text {peak }}$, is calculated as

$$
\begin{aligned}
P_{\text {peak }}= & H D^{\prime} \gamma^{\prime}-\left(\frac{D}{2}+E\right)^{2} \sin (\theta) \cos (\theta) \gamma^{\prime} \\
& -\left(\frac{\pi}{2}-\theta\right) \frac{D^{2}}{4} \gamma^{\prime}+H^{\prime 2} \tan (\psi) \gamma^{\prime} \\
& +H^{\prime 2} \gamma^{\prime}\left[\tan \left(\phi_{\text {peak }}\right)-\tan (\psi)\right] \\
& \times\left[\frac{1+K_{0}}{2}-\frac{1-K_{0}}{2} \cos (2 \psi)\right]
\end{aligned}
$$

where $\theta, E, H^{\prime}$ and $D^{\prime}$ are variables defined by the pipeline geometry as defined in Fig. 3. This method is applicable for pipelines with lateral extent of fins $\left(D^{\prime}\right)$ greater than the original diameter $(D)$.

Normalising this result to obtain the dimensionless uplift factor, $F_{\text {up }}$, and simplifying, equation (3) reduces to

$$
\begin{aligned}
\frac{P_{\text {peak }}}{H D \gamma^{\prime}}= & N_{\gamma}=\frac{D^{\prime}}{D}-\frac{(D / 2+E)^{2} \sin (\theta) \cos (\theta)}{H D} \\
& -\frac{(\pi / 2-\theta)}{4} \frac{D}{H}+F_{\text {up }} \frac{H^{\prime 2}}{H D}
\end{aligned}
$$




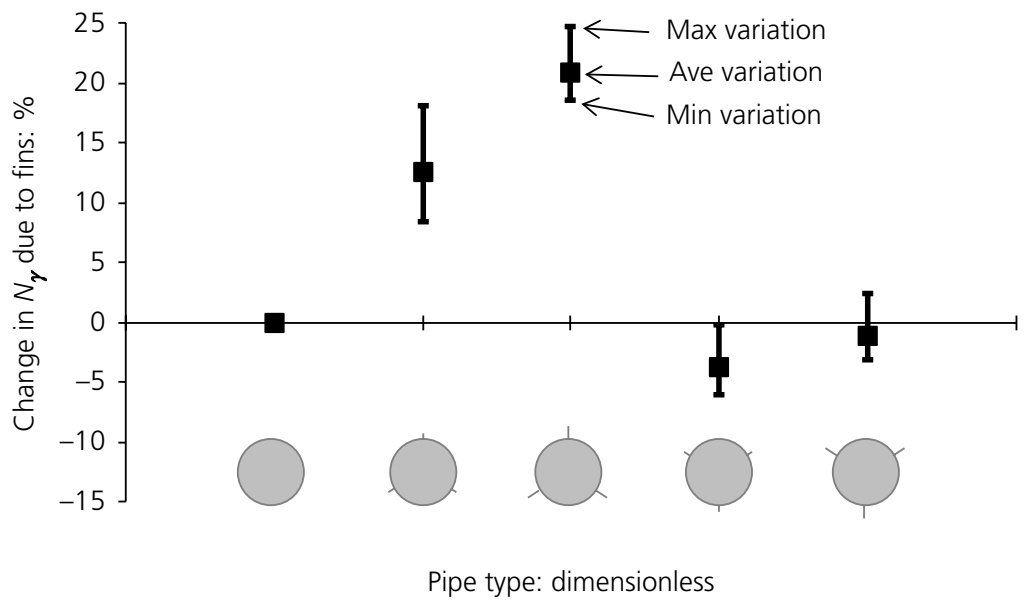

(a)

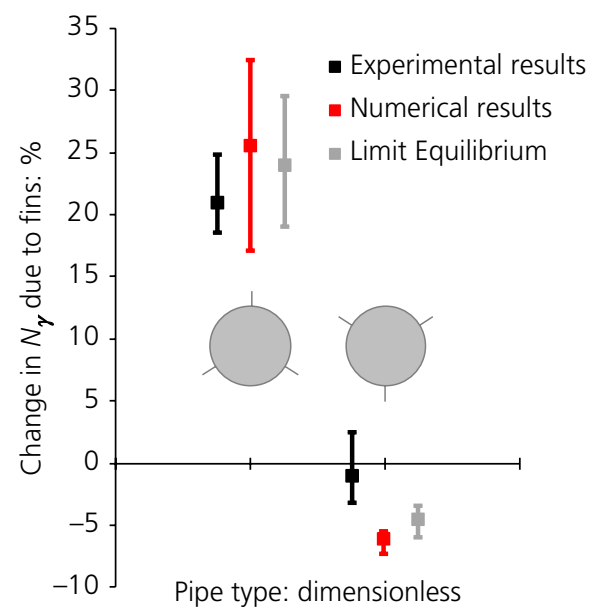

(b)

Fig. 5. Variation in peak uplift resistance relative to pipe 1: (a) experimental results and (b) numerical analysis and limit equilibrium results for pipes 3 and 5

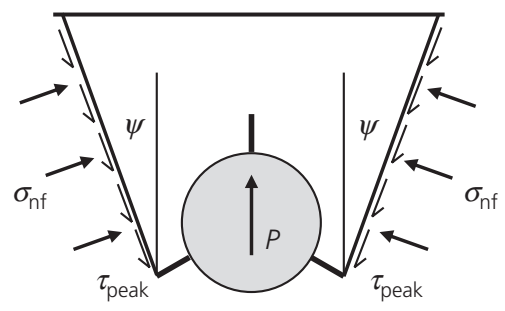

Fig. 6. Geometry schematic for limit equilibrium solution (equation (3-5))

where the uplift factor, $F_{\text {up }}$, is defined as

$$
\begin{aligned}
F_{\text {up }}= & \tan (\psi)+\left[\tan \left(\phi_{\text {peak }}\right)-\tan (\psi)\right] \\
& \times\left[\frac{1+K_{0}}{2}-\frac{1-K_{0}}{2} \cos (2 \psi)\right]
\end{aligned}
$$

This limit equilibrium solution gives good predictions of the change in uplift resistance due to the fins, as shown in Fig. 5(b) (for $R_{\mathrm{d}}=25 \%$ ). It also provides a simple explanation for the relative performance of the centre-up and centre-down arrangements. The centre-up arrangement triggers longer and deeper shear planes that encompass a higher weight of soil, whereas the centre-down arrangement leads to shorter, shallow shear planes lifting less soil. The numerical results provide a further comparison and are also shown in Fig. 5(b) for the rough interface. These analyses used the same soil strength and dilation parameters as the limit equilibrium solution, and assumed elastic parameters (Table 2). The variation in resistance due to the fins is similar to the experimental and limit equilibrium results.

In addition to predicting accurately the relative resistance with and without fins, the limit equilibrium solution also gives reasonable absolute estimates of the uplift resistance, when using the parameters given in Table 1 and taking a relative density range from 20 to $30 \%$ (Fig. 7). The numerical results are also shown in Fig. 7 for both smooth interface (open diamonds) and rough interface (open triangles) conditions.

In summary, the predictions are generally consistent with the experimental values, including the relative resistance with and without fins in each orientation, apart from the smooth interface numerical results for pipe 3, which overpredict the experimental results by about $11-21 \%$. The numerical results tend to overpredict the experimental resistance, while the limit equilibrium calculations underpredict the results and generally provide a conservative estimate of the available resistance.

\section{Comparison of failure mechanisms at peak resistance}

Contours of the soil vertical displacement field at peak resistance normalised by the pipe displacement (i.e. $\delta z_{\text {soil }} / \delta z_{\text {pipe }}$ ) for pipes 1, 3 and 5 are shown in Fig. 8, where the left-hand sides of each figure shows OptumG2 numerical results and the right-hand side shows PIV results. OptumG2 results in Fig. 8 were calculated using the dilation angles listed in Table 2 and a smooth interface.

The experimentally determined mechanism involves a zone of uplifted soil above the pipe that extends to less than $2 D$ above the pipe, with a reduction in soil displacement with height above the pipe and circulation of soil from above to beneath the pipe. The circulation mechanism is most evident for pipe 1, whereas the fins appear to limit the flow of soil to beneath the pipe for pipes 3 and 5. A similar mechanism was observed by Bransby \& Ireland (2009) in experiments with a plain pipe in loose sand. While the observed mechanism is not identical to that assumed in the inclined slip-line model (Fig. 6), it is more consistent with the concept of lifting a block of soil ahead of the pipe than the flow-around mechanism that is generally assumed for clay, and that is also expected for a much more deeply buried pipe in sand.

Overall, the numerical and experimental failure mechanisms are similar, although the volume of soil mobilised above the pipe tends to be overestimated numerically. Figure 9 shows that a second set of numerical results obtained using a dilation angle of $-2^{\circ}$ yields mechanisms that are more consistent with those observed experimentally. This change reduces the calculated resistance for the smooth interface by $14 \%$ (pipe 1), $6 \%$ (pipe 3) and 9\% (pipe 5) relative to the calculations obtained using the parameters in Table 2, and varies from the experimental results by $-10 \%$ (pipe 1 ), $15 \%$ (pipe 3) and $-13 \%$ (pipe 5). Vanden Berghe et al. (2005) adopted a similar approach to elicit a localised flow-round mechanism in their numerical analyses of pipe uplift.

For the current numerical analyses, a combined vertical lifting and circulation mechanism was only initiated with a fully smooth pipe interface, whereas a rough interface resulted in a purely vertical slip wedge-type failure. Figure 7 suggests that the difference between these two interface 


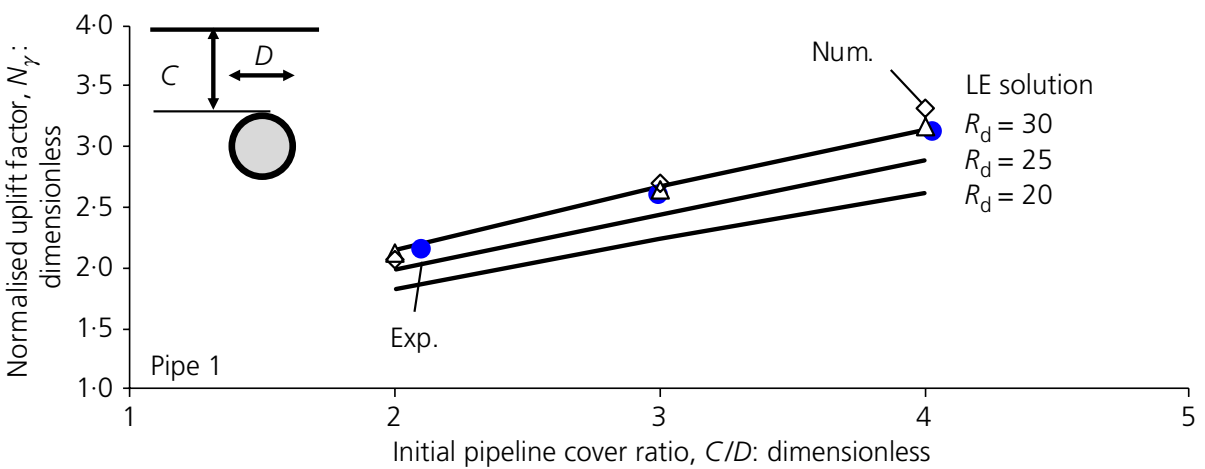

(a)

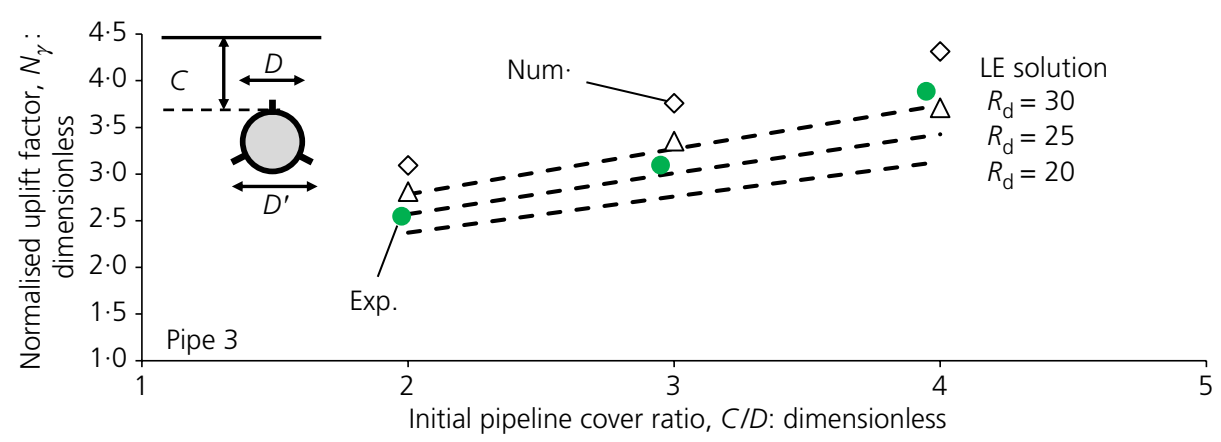

(b)

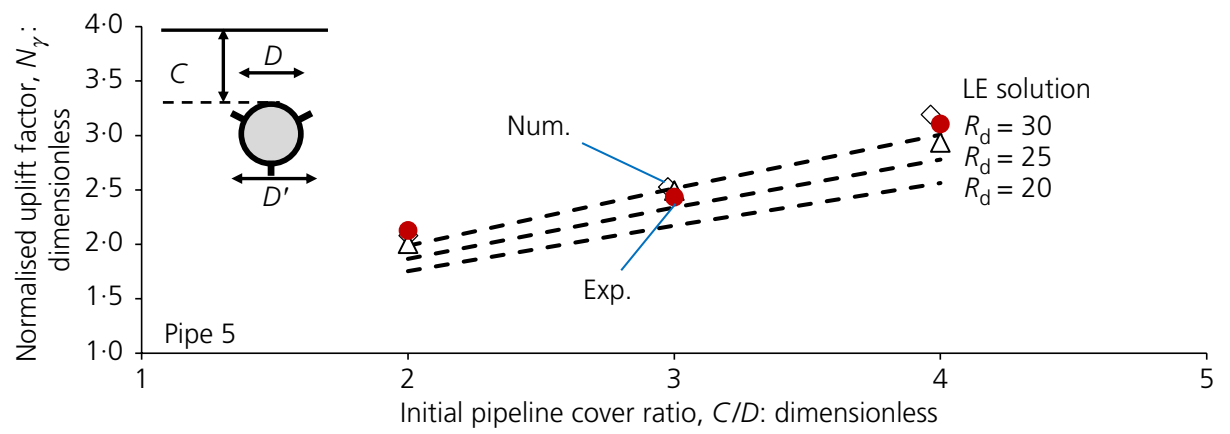

(c)

Fig. 7. Peak measured normalised uplift factor: (a) pipe 1; (b) pipe 3; (c) pipe 5

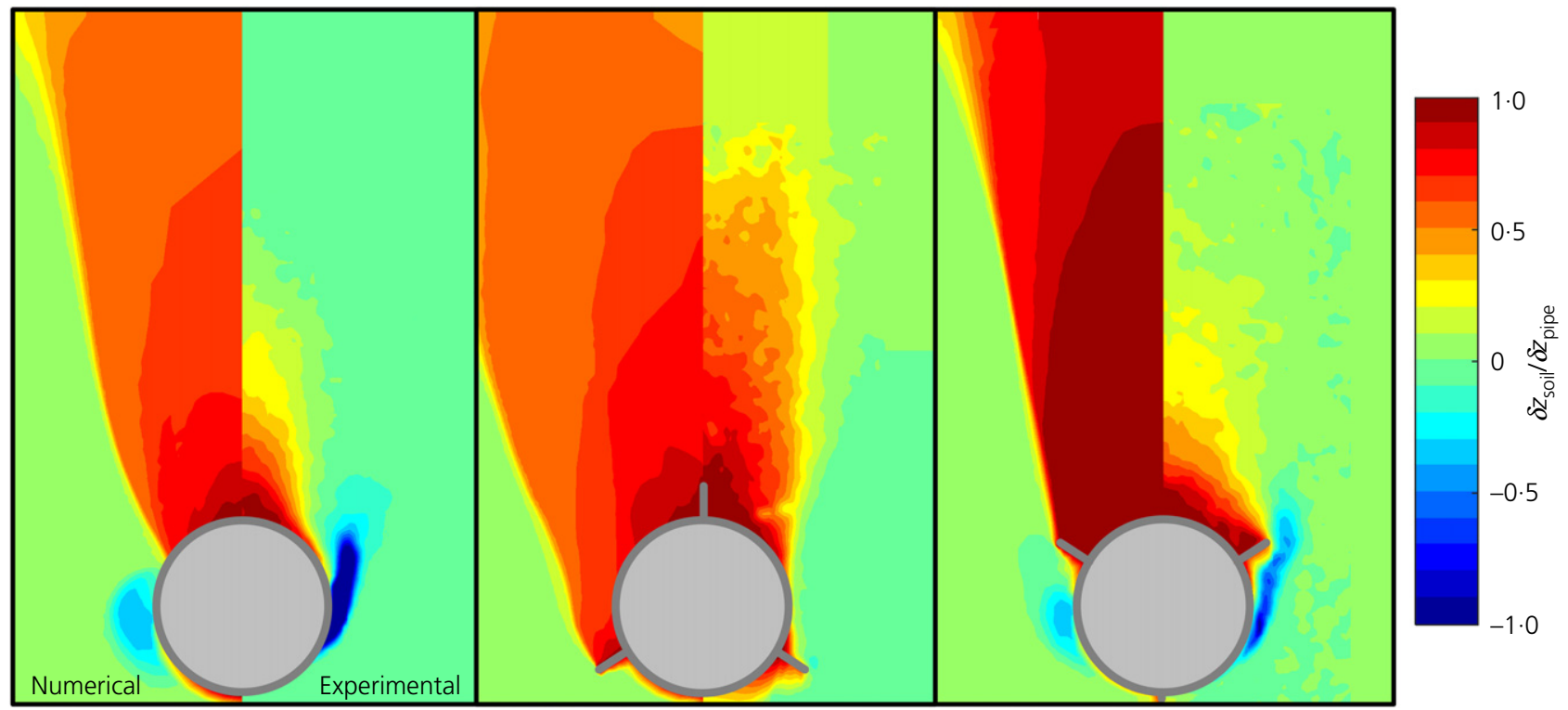

Fig. 8. Uplift mechanisms at peak resistance - comparison of experimental observations and numerical results using initial soil property set (left-hand side: numerical results; right-hand side: experimental results) 


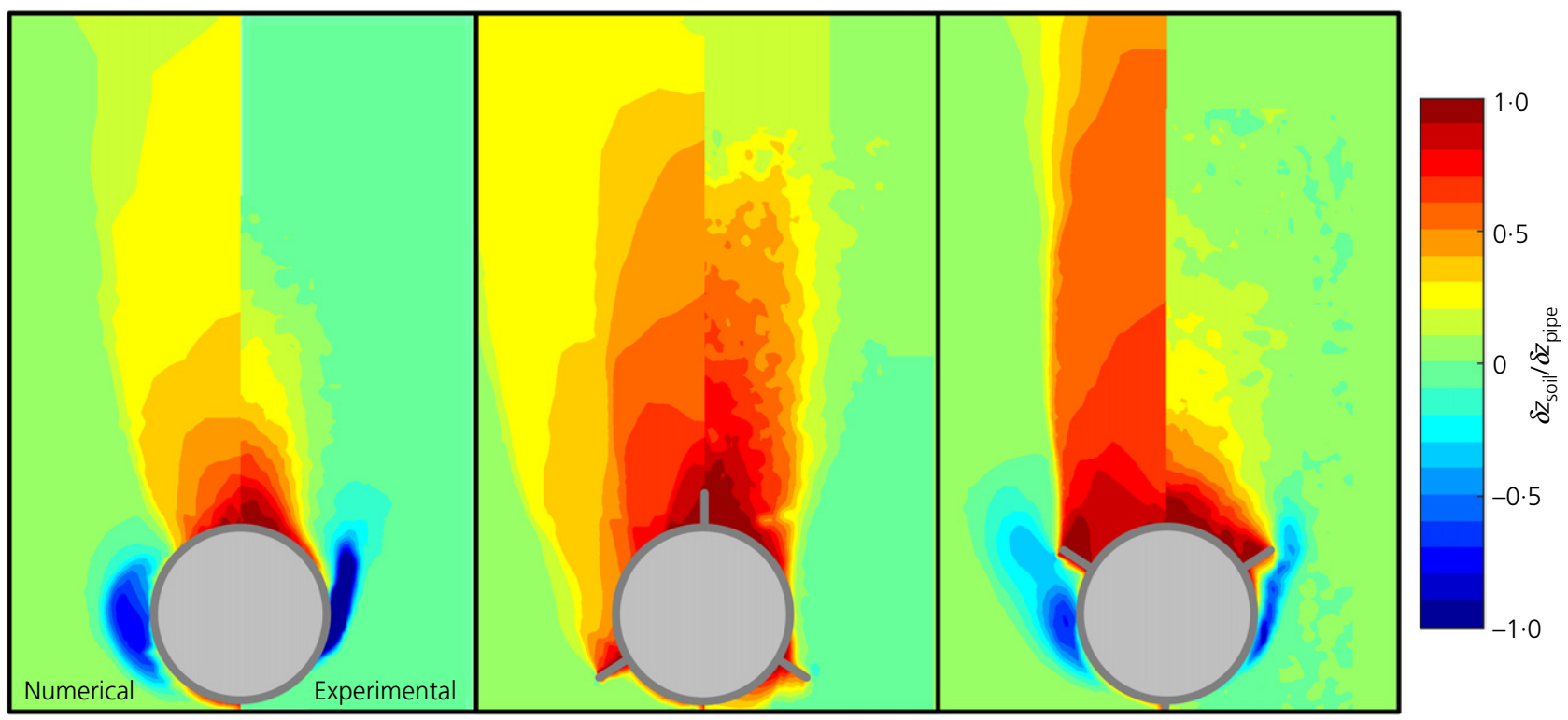

Fig. 9. Uplift mechanisms at peak resistance - comparison of experimental observations and numerical results using a reduced dilation angle (left-hand side: numerical results; right-hand side: experimental results)

conditions, and by extension the corresponding mechanisms, is within $14 \%$ for all cases.

\section{CONCLUSIONS}

A series of model tests were conducted in loose silica sand to investigate the effect of radial fins extending by up to $20 \%$ of the pipe diameter on the uplift resistance of buried pipelines. The tests showed a reasonable improvement in the purely vertical peak uplift resistance ranging from 8 to $25 \%$, depending on embedment depth and fin length, when oriented in the centre-up arrangement.

The observed trends of changing fin configuration and embedment depth were captured both numerically and using a limit equilibrium solution. Predicted peak uplift resistances using both methods were broadly consistent, with the limit equilibrium solution providing a slightly conservative bias. In this context - and for the pipe cover ratios and soil densities considered here - the limit equilibrium solution is considered an appropriate method to predict the uplift resistance of shallowly embedded pipelines and to quantify how this resistance may be affected by geometry adjustments.

\section{ACKNOWLEDGEMENTS}

This work forms part of the research and development activities for the Offshore Engineering Division, Technip (UK). The testing activity was performed at the Centre for Offshore Foundation Systems (COFS), currently supported as a node of the Australian Research Council Centre of Excellence for Geotechnical Science and Engineering (grant CE110001009) and through the Fugro Chair in Geotechnics, the Lloyd's Register Foundation Chair and Centre of Excellence in Offshore Foundations and the Shell EMI Chair in Offshore Engineering (held by the third author).

\section{REFERENCES}

Bolton, M. D. (1986). The strength and dilatancy of sands. Géotechnique 36, No. 1, 65-78, http://dx.doi.org/10.1680/geot. 1986.36.1.65.

Bransby, M. F. \& Ireland, J. (2009). Rate effects during pipeline upheaval buckling in sand. Proc. Instn Civil Engrs - Geotech. Engng 162, No. GE5, 247-256.
Cheuk, C. Y., White, D. J. \& Bolton, M. D. (2008). Uplift mechanisms of pipes buried in sand. J. Geotech. Geoenviron. Engng 134, No. 2, 154-163.

De Catania, S., Breen, J., Gaudin, C. \& White, D. J. (2010). Development of multiple-axis actuator control system. Proceedings of the 7th international conference on physical modelling in geotechnics (ICPMG), London, UK, pp. 325-330. London, UK: Taylor \& Francis Group.

Dicken, E. A. (1994). Uplift resistance of buried pipelines in sand. Soils Found. 34, No. 2, 41-48.

DNV (Det Norske Veritas) (2007). DNV-RP-F110: Global buckling of submarine pipelines - structural design due to high temperature/high pressure. Oslo, Norway: DNV.

Drescher, A. \& Detournay, E. (1993). Limit load in translational failure mechanisms for associative and non-associative materials. Géotechnique 43, No. 3, 443-456, http://dx.doi.org/ 10.1680/geot.1993.43.3.443.

Gaudin, C., White, D. J., Boylan, N., Breen, J., Brown, T., De Catania, S. \& Hortin, P. (2009). A wireless high-speed data acquisition system for geotechnical centrifuge model testing. Meas. Sci. Technol. 20, No. 9, Article number 095709.

Ivanović, A. \& Oliphant, J. (2014). Uplift mobilisation resistance of subsea pipelines in loose sand. Géotech. Lett. 4, No. 3, 217-222, http://dx.doi.org/10.1680/geolett.13.00066.

Lee, K. K. (2009). Investigation of potential spudcan punch-through failure on sand overlying clay soils. $\mathrm{PhD}$ thesis, The University of Western Australia, Crawley, Australia.

Merifield, R. S. \& Sloan, S. W. (2006). The ultimate pullout capacity of anchors in frictional soils. Can. Geotech. J. 43, No. 8, $852-868$.

O'Loughlin, C. D. \& Barron, B. (2012). Capacity and keying response of plate anchors in sand. Proceedings of the 7 th international conference on offshore site investigation and geotechnics, London, UK, pp. 649-655. London, UK: Society for Underwater Technology.

OptumCE (2016). OptumG2. Newcastle, Australia: OptumCE. See http://www.optumce.com/ (accessed 12/12/2016).

Smith, C. C. (2012). Limit loads for a shallow anchor/ trapdoor embedded in a non-associative Coulomb soil. Géotechnique 62, No. 7, 563-571, http://dx.doi.org/10.1680/ geot.10.P.136.

Stanier, S. A. \& White, D. J. (2013). Improved image-based deformation measurement in the centrifuge environment. Geotech. Test. J. 36, No. 6, 1-14.

Stanier, S. A., Blaber, J., Take, W. A. \& White, D. J. (2016). Improved image-based deformation measurement for geotechnical applications. Can. Geotech. J. 53, No. 5, 727-739. 
Trautmann, C. H., O’Rourke, T. D. \& Kulhawy, F. H. (1985). Uplift force-displacement response of buried pipe. J. Geotech. Engng 111, No. 9, 1061-1076.

Vanden Berghe, J. F., Cathie, D. \& Ballard, J. C. (2005). Pipeline uplift mechanisms using finite element analysis. Proceedings of the 16th international conference of soil mechanics and foundation engineering, Osaka, Japan, pp. 1801-1804. Osaka, Japan: IOS Press.
White, D. J., Cheuk, C. Y. \& Bolton, M. D. (2008a). The uplift resistance of pipes and plate anchors buried in sand. Géotechnique 58, No. 10, 771-779, http://dx.doi.org/10.1680/ geot.2008.3692.

White, D. J., Teh, K. L., Leung, C. F. \& Chow, Y. K. (2008b). A comparison of the bearing capacity of flat and conical circular foundations on sand. Géotechnique 58, No. 10, 781-792, http://dx.doi.org/10.1680/geot.2008.3781.

\section{HOW CAN YOU CONTRIBUTE?}

To discuss this paper, please submit up to 500 words to the editor at journals@ice.org.uk. Your contribution will be forwarded to the author(s) for a reply and, if considered appropriate by the editorial board, it will be published as a discussion in a future issue of the journal. 